\title{
Serial Analysis of Gene Expression in Plasmodium berghei salivary gland sporozoites
}

Isabelle Rosinski-Chupin*1, Thomas Chertemps ${ }^{1}$, Bertrand Boisson ${ }^{2}$, Sylvie Perrot ${ }^{1}$, Emmanuel Bischoff ${ }^{3}$, Jérôme Briolay ${ }^{4}$, Pierre Couble ${ }^{5}$, Robert Ménard ${ }^{2}$, Paul Brey ${ }^{1}$ and Patricia Baldacci*2

\begin{abstract}
Address: ${ }^{1}$ Biochimie et Biologie Moléculaire des Insectes, Institut Pasteur, 28 rue du Dr Roux, 75724, Paris cedex 15, France, ${ }^{2}$ Biologie et Génétique du Paludisme, Institut Pasteur, 28 rue du Dr Roux, 75724, Paris cedex 15, France, ${ }^{3}$ Plateforme 2: Puces à ADN, Institut Pasteur, 28 rue du Dr Roux, 75724, Paris cedex 15, France, ${ }^{4}$ DTAMB, Université de Lyon; IFR 41; 43 boulevard du 11 Novembre 1918, 69622 Villeurbanne cedex, France and ${ }^{5}$ Centre de Génétique Moléculaire et Cellulaire, UMR 5534, C.N.R.S.-Université de Lyon, 69622 Villeurbanne cedex, France

Email: Isabelle Rosinski-Chupin* - ichupin@pasteur.fr; Thomas Chertemps - tcher@pasteur.fr; Bertrand Boisson - boisson@pasteur.fr; Sylvie Perrot - sperrot@pasteur.fr; Emmanuel Bischoff - bischoff@pasteur.fr; Jérôme Briolay - briolay@biomserv.univ-lyon1.fr; Pierre Couble - Pierre.Couble@univ-lyon1.fr; Robert Ménard - rmenard@pasteur.fr; Paul Brey - pbrey@pasteur.fr;

Patricia Baldacci* - baldacci@pasteur.fr

* Corresponding authors
\end{abstract}

Published: 19 December 2007

BMC Genomics 2007, 8:466 doi:10.1 186/1471-2164-8-466

This article is available from: http://www.biomedcentral.com/147/-2/64/8/466

(c) 2007 Rosinski-Chupin et al; licensee BioMed Central Ltd.

This is an Open Access article distributed under the terms of the Creative Commons Attribution License (http://creativecommons.org/licenses/by/2.0), which permits unrestricted use, distribution, and reproduction in any medium, provided the original work is properly cited.
Received: 18 April 2007

Accepted: 19 December 2007

\begin{abstract}
Background: The invasion of Anopheles salivary glands by Plasmodium sporozoites is an essential step for transmission of the parasite to the vertebrate host. Salivary gland sporozoites undergo a developmental programme to express genes required for their journey from the site of the mosquito bite to the liver and subsequent invasion of, and development within, hepatocytes. A Serial Analysis of Gene Expression was performed on Anopheles gambiae salivary glands infected or not with Plasmodium berghei and we report here the analysis of the Plasmodium sporozoite transcriptome.
\end{abstract}

Results: Annotation of 530 tag sequences homologous to Plasmodium berghei genomic sequences identified 123 genes expressed in salivary gland sporozoites and these genes were classified according to their transcript abundance. A subset of these genes was further studied by quantitative PCR to determine their expression profiles. This revealed that sporozoites modulate their RNA amounts not only between the midgut and salivary glands, but also during their storage within the latter. Among the 123 genes, the expression of 66 is described for the first time in sporozoites of rodent Plasmodium species.

Conclusion: These novel sporozoite expressed genes, especially those expressed at high levels in salivary gland sporozoites, are likely to play a role in Plasmodium infectivity in the mammalian host.

\section{Background}

The sporozoite is the stage of the malaria parasite transmitted from the mosquito vector to the mammalian host. The success of infection depends on the sporozoites leav- ing their site of inoculation in the dermis, rapidly attaining the liver, invading hepatocytes, and developing therein [1-4]. This results in the release of thousands of merozoites from the infected hepatocytes that subse- 
quently invade red blood cells, causing the malaria disease [5]. Sporozoites are formed within oocysts of the mosquito midgut and are initially poorly infectious. They migrate to mosquito salivary glands (SG) and must undergo a developmental programme, with concomitant changes in gene expression, in order to become highly infectious to the mammalian host. These SG sporozoites exhibit a circular gliding movement and in certain conditions can elicit a strong protective immune response in the mammalian host [6-8].

Recent technological advances have improved our understanding, at the molecular level, of the Plasmodium parasite including the less well known sporozoite stage. The completion of the Plasmodium falciparum (P. falciparum) genome sequence allowed the analysis of gene expression at different stages of the parasite life cycle with microarrays [9]. The data showed that approximately 2000 genes are expressed in SG sporozoites, 500 of which are expressed at high levels and over a 100 of these are not expressed at significant levels in blood stages. In addition, proteomic analyses detected 274 proteins in P. falciparum sporozoites $[10,11]$.

Plasmodium species infecting rodents are powerful laboratory models as they are more easily amenable to genetic studies and their genomes have also been sequenced $[11,12]$. However, the transcriptome of sporozoites from these species is less well known and has been obtained mainly from Plasmodium yoelii ( $P$. yoelii) cDNA libraries [13] and Suppressive Subtractive Hybridisation studies $[14,15]$. In addition, 119 proteins have been identified in Plasmodium berghei (P. berghei) sporozoites, of which 34 are sporozoite specific (PlasmoDB release 5.1).

We recently reported a SAGE aimed at characterising Anopheles gambiae (A. gambiae) SG genes that are differentially expressed in response to infection with $P$. berghei sporozoites [16]. In that study 530 tag sequences, found exclusively in libraries from infected mosquitoes, were identical to $P$. berghei genomic sequences, and 41 of these were readily annotated. Considering the data presently available for the transcriptome of $P$. berghei sporozoites, we decided that it would be worthwhile to annotate the remaining tags. SAGE allows gene-expression-profiling based on the quantification of short 14-15 nucleotide (nt) sequence tags, each sequence being, in theory, associated with the transcript of a single gene. It provides an overall estimation of the abundance of transcripts, while requiring no a priori information about the sequence of the transcripts to be studied $[17,18]$. However, only short cDNA sequences, usually located in the 3'UTR, are obtained and consequently the attribution of a tag sequence to a gene is highly dependent on the quality of annotation of the genome of the organism studied and available cDNA or EST studies $[19,20]$. On the other hand, positioning tags on the genomic sequence can provide information on both the orientation of a transcript and the length of the 3' UTR.

The tags from our SAGE were annotated by combining information on their position in the P. berghei genomic sequences, predicted gene models and ESTs from $P$. berghei and $P$. yoelii. We unambiguously identified 123 genes expressed in $P$. berghei sporozoites, of which 66 are detected for the first time in rodent Plasmodium species. The hierarchical classification of these transcripts according to the abundance of the tags was confirmed by qPCR and the characterisation of the gene structure and/or gene expression was undertaken for some. Finally, our results provide evidence that mRNA levels may vary not only between midgut and SG sporozoites but also during storage of the sporozoites in the SG.

\section{Results}

\section{Annotation of Plasmodium berghei tags: rationale}

SAGE libraries were constructed from four different SG RNA preparations: SG isolated from A. gambiae mosquitoes 14 , or 18 , days after a blood meal on $P$. berghei infected mice and SG isolated 14, or 15-18, days after feeding on uninfected mice [16]. Sequence analysis showed that among the tags identified in the infected SG libraries, 17181 were absent from uninfected SG libraries and were thus considered as potential $P$. berghei sequences (see Figure 1). These sequences were then screened using the following criteria: 1) to be found more than once in the cumulative libraries, 2) to give a single hit in the $P$. berghei genome, 3 ) to be derived from the most 3' NlaIII site predicted in the annotated gene sequence in the sense orientation ("primary" tags in Figure 1) or to be found within $500 \mathrm{nt}$ of the stop codon of an annotated gene in the sense orientation.

We found 2154 tag sequences at least twice in the cumulative libraries and 530 of these gave one or more perfect matches by BLASTN comparison on $P$. berghei genomic sequences and annotated genes. These tag sequences and their annotations are provided in Additional file 1. We discarded from further analysis 162 tags that gave multiple hits in the genome due to the impossibility of assigning them to a unique gene. Of the 368 tags that gave a single hit in the genome, 166 were found within annotated genes and 62 of these were derived from the most 3' NlaIII predicted site.

Sampling of the 3' untranslated regions of about 30 Plasmodium genes showed that $77 \%$ of them were $500 \mathrm{nt}$ in length (I.C. unpublished observation). Therefore, we analysed in more detail the position in the genome of the 202 tags that were not found within annotated genes. Sixty- 


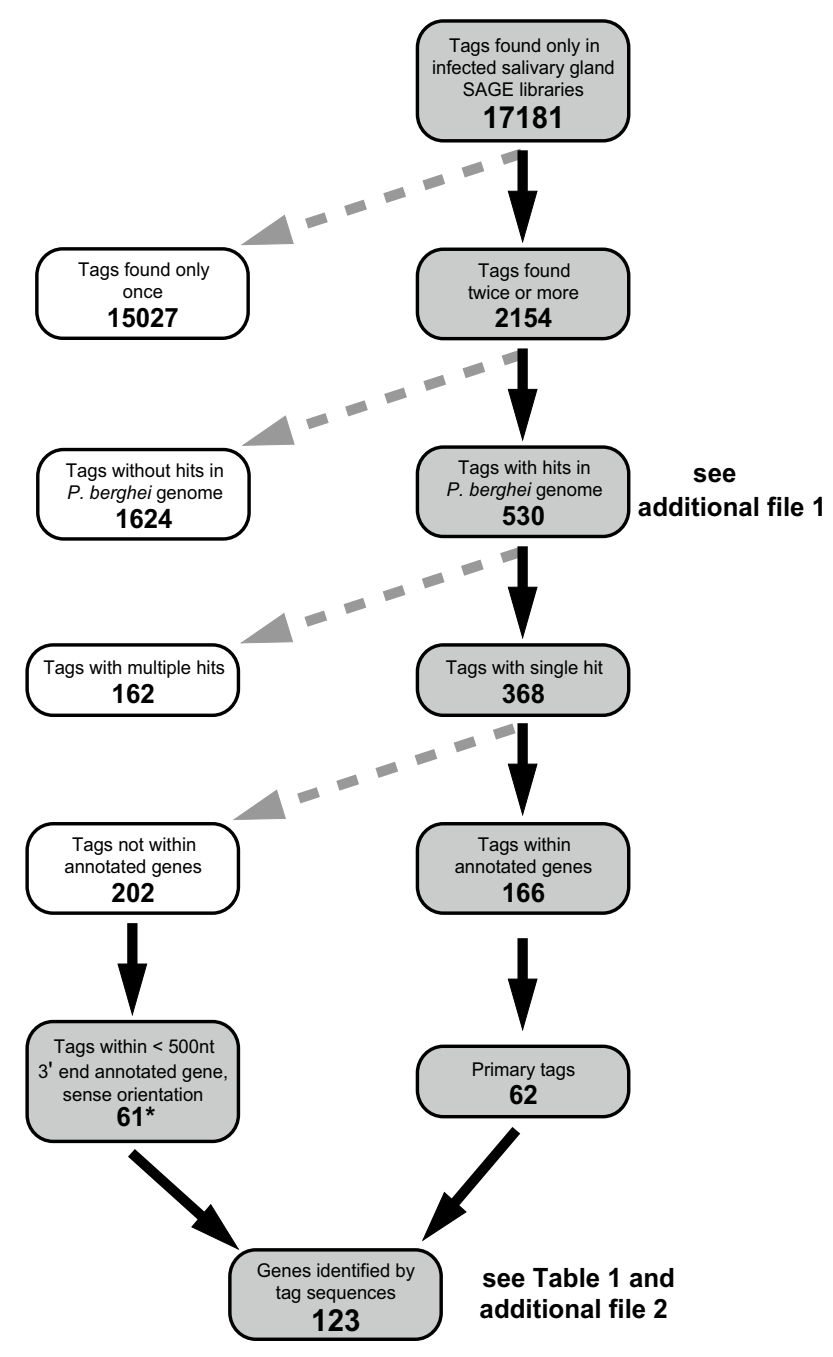

Figure I

Flow chart of the rationale used to select Tag sequences from the SAGE library. Shaded boxes correspond to tag sequences retained, clear boxes correspond to tag sequences rejected.

three tag sequences, found within $500 \mathrm{nt}$ downstream of the stop codon of an annotated gene and in the sense orientation, were retained in the analysis as it seemed likely that they came from the 3' end of the adjacent genes. As two genes were identified with two different tag sequences respectively, only one tag was retained for each gene, resulting in a total of 61 (see Figure 1).

In total, 123 identifying tag sequences fulfilled all our criteria (see Table 1 and Additional file 2). BLASTN analysis of the 123 genes identified by these tags showed that 55 aligned with known transcripts from $P$. yoelii or $P$. berghei sporozoites, whereas the remaining 68 did not. Among the latter, proteomic approaches have detected
PB000876.00.0 in sporozoites and a study by Ishino et al.[21] showed that PB000892.00.0 (Pbs36) is also present. It should be noted that the criteria used have resulted in the elimination of the majority of tag sequences, including several tags corresponding to genes known to be expressed in SG sporozoites (see Additional file 1). For example, two tags aligned with PB001026.00.0, coding for circumsporozoite protein (CS). The most abundant tag, found 77 times, gave 4 hits in the genome and the second tag sequence was in the antisense orientation. Although it is likely that the most abundant tag originated from the CS transcript, it was not taken into account in order to be consistent in the analysis. Another example concerned two tags aligning with PB000892.03.0 (UIS3), a gene known to be upregulated in sporozoites [14]. Again the most abundant tag gave multiple hits in the genome and the second was in the antisense orientation.

Taken together this SAGE analysis has identified 66 novel sporozoite expressed genes (indicated as SIS on Table 1).

\section{Validation of SAGE data}

SAGE, like microarrays, is designed to give quantitative information on gene expression and the interpretation of the results depends on correct gene identification. This identification is not always straightforward in P. berghei since genomic sequence clusters are generally shorter than in $P$. falciparum; this results in the prediction of a large number of truncated genes, often lacking $5^{\prime}$ or 3 ' ends. In addition, there are less EST ressources.

As a first step towards confirming the gene expression in sporozoites and validating tag annotation, we obtained more accurate data on gene structure and organization, by clustering ESTs and comparing with $P$. yoelii and $P$. chabaudi orthologous sequences. In Table 1, 15 genes (indicated by ${ }^{*}$ ) have been manually reannotated resulting in a different structure and a longer ORF than that predicted in the databases. These structures have been confirmed for 13 genes by RT-PCR on sporozoite RNA (see Additional file 2). For genes that are split between two genomic clusters, the intervening fragment was cloned and sequenced (see Additional file 2).

To confirm the identification of the 66 novel genes expressed in salivary gland sporozoites, RT-PCR experiments were performed. PCR fragments were obtained for all of them indicating that these genes are truely expressed (Additional file 3).

The number of times a tag sequence is identified in a SAGE library is expected to correlate with the relative abundance of the steady state mRNA [17]. To determine whether the SAGE data correctly reflects transcript abun- 
Table I: List of I 23 genes identified by SAGE in P. berghei salivary gland sporozoites

\begin{tabular}{|c|c|c|c|c|c|c|c|c|c|}
\hline & \multirow[b]{2}{*}{ Tag ID } & \multicolumn{3}{|c|}{ times found } & \multirow[b]{2}{*}{ GeneDB ID } & \multirow[b]{2}{*}{ Known as } & \multirow[b]{2}{*}{$\begin{array}{l}\text { Sporozoite } \\
\text { expression }\end{array}$} & \multirow[b]{2}{*}{ Pf orthologue } & \multirow[b]{2}{*}{$\begin{array}{l}\text { Predicted } \mathrm{Pb} / \mathrm{Pf} \text { protein domain } \\
\text { and/or function }\end{array}$} \\
\hline & & dI 4 & d18 & total & & & & & \\
\hline \multirow[t]{5}{*}{ group I } & $\operatorname{tag} 335$ & 60 & 39 & 99 & PB402615.00.0* & & d & Pfgenefinder_63r & \\
\hline & $\operatorname{tag} 183$ & 6 & 89 & 95 & PBI0055I.00.0 & UIS4 & a, $d$ & -- & SP, TM \\
\hline & tag 190 & 9 & 59 & 68 & PBI0746I.00.0 & UIS7 & d & -- & TM \\
\hline & $\operatorname{tag} 269$ & 6 & 25 & 31 & PB000374.03.0 & TRAP & $d, I, P$ & PFI3_020I & SP, vWA-like, TSPI \\
\hline & $\operatorname{tag} 226$ & 11 & 13 & 24 & PB00I063.00.0 & S23 & $\mathrm{d}, \mathrm{I}$ & PF08_0088 & Pb-reticulocyte binding, SP, TM \\
\hline \multirow[t]{8}{*}{ group 2} & $\operatorname{tag} 435$ & 10 & 7 & 17 & PB000252.01.0 & SI3, SPECT2 & $\mathrm{d}, \mathrm{Pb}, \mathrm{I}, \mathrm{P}$ & PFD0430c & SP, MAC/Perforin domain \\
\hline & $\operatorname{tag} 168$ & 4 & 12 & 16 & PB000317.00.0* & & d, I, P & PF08_0008 & SP, TM, GPI \\
\hline & $\operatorname{tag} 146$ & 8 & 8 & 16 & PB000881.01.0 & S2I/PbTRSP & $d, I, P$ & PFA0200w & TM, TSPI \\
\hline & $\operatorname{tag} 112$ & 11 & 2 & 13 & PB000649.01.0 & ECPI & $\Delta, \mathrm{I}, \mathrm{P}$ & PFB0325c & Papain family cysteine protease \\
\hline & tag 110 & 2 & 11 & 13 & PBI040I7.00.0 & $S 12$ & d & -- & SP \\
\hline & $\operatorname{tag} 200$ & 2 & 9 & 11 & PB000400.01.0* & SISI & $\Delta, \mathrm{l}$ & PFE0395c & $\begin{array}{l}\text { Pf38, Sexual stage antigen, SP, TM, } \\
\text { GPI }\end{array}$ \\
\hline & $\operatorname{tag} 75$ & 3 & 8 & 11 & PB000484.00.0 & UISIO/PbPL & a & PFFI420w & $\begin{array}{l}\text { Phosphatidylcholine-sterol } \\
\text { acyltransferase }\end{array}$ \\
\hline & $\operatorname{tag} 50$ & 4 & 6 & 10 & PB000891.00.0 & Pbs36p & $d, I$ & PFD02I5c & Pf52, Sexual stage antigen, SP \\
\hline \multirow[t]{35}{*}{ group 3} & $\operatorname{tag} 76$ & I & 8 & 9 & PBI04912.00.0* & & $d, I$ & PFII_0283 & SP, TM \\
\hline & $\operatorname{tag} 264$ & 3 & 5 & 8 & $A B \mid 25370$ & SPECT & $d, I, P$ & MALI3PI.2I2 & $\mathrm{SP}$ \\
\hline & tag 278 & 4 & 4 & 8 & PB000757.02.0 & SIS2 & $\Delta, \mathrm{I}, \mathrm{P}$ & PFI4_0425 & Fructose-I, 6-bisphosphate aldolase \\
\hline & $\operatorname{tag} 319$ & I & 7 & 8 & PBI08190.00.0* & UISI & a & -- & $\begin{array}{l}\text { Serine/Threonine protein kinases, } 9 \\
\text { TM }\end{array}$ \\
\hline & $\operatorname{tag} 136$ & 2 & 5 & 7 & PBI00963.00.0 & & d & -- & Guanylyl cyclase, TM \\
\hline & $\operatorname{tag} 245$ & 0 & 6 & 6 & PB000780.01.0* & & $d, I$ & PFII230c & $4 \mathrm{TM}$, asparagine-rich \\
\hline & $\operatorname{tag} 530$ & 0 & 5 & 5 & PB000264.00.0* & & $d$ & PFI4_0044 & SP \\
\hline & $\operatorname{tag} 118$ & 0 & 5 & 5 & PB0004II.03.0* & SIS3 & $\Delta$ & -- & \\
\hline & $\operatorname{tag} 294$ & 1 & 4 & 5 & PB000464.00.0 & S25 & d, I, P & PFL0545w & Kinesin-related protein \\
\hline & $\operatorname{tag} 280$ & 0 & 5 & 5 & PB0008I7.02.0 & & d, I, P & PF08_0054 & Heat shock $70 \mathrm{kDa}$ proteinn \\
\hline & $\operatorname{tag} 268$ & 1 & 4 & 5 & PB00I070.03.0 & & d & PFF0685c & Fe-only hydrogenase \\
\hline & $\operatorname{tag} 193$ & I & 4 & 5 & PBI0II72.00.0 & & $d$ & -- & \\
\hline & tag 92 & 2 & 2 & 4 & PB000I6I.03.0 & & $d, I$ & PFI0955w & sugar transporter, 6TM \\
\hline & $\operatorname{tag} 201$ & 0 & 4 & 4 & PB000787.03.0 & SIS4 & $\Delta, \mathrm{l}$ & PFI0320w & Arginase family \\
\hline & $\operatorname{tag}|0|$ & 0 & 4 & 4 & PBI05090.00.0 & SIS5 & $\Delta$ & -- & TM \\
\hline & $\operatorname{tag} 233$ & 1 & 3 & 4 & PB 106293.00.0* & & d & MALI3PI.365 & SNARE \\
\hline & $\operatorname{tag} 188$ & 2 & 2 & 4 & PBI07843.00.0* & SIS6 & $\Delta, \mathrm{I}$ & PFIO_0290 & TM \\
\hline & $\operatorname{tag} 62$ & 3 & 1 & 4 & PBI08391.00.0 & & d, I, P & PF08_0072 & $\mathrm{TM}$ \\
\hline & $\operatorname{tag} 276$ & I & 3 & 4 & PB000632.00.0 & SIS7 & $\Delta, \mathrm{I}$ & PFI4_05I8 & nifU protein, putative \\
\hline & tag 354 & 3 & 0 & 3 & PB000 175.03.0* & SIS8 & $\Delta, \mathrm{I}$ & PFD0915w & TM \\
\hline & tag $|7|$ & 1 & 2 & 3 & PB000416.02.0 & & $d, I$ & PFD0825c & $\begin{array}{l}\text { RNA-binding protein of pumilio/ } \\
\text { mpt5 family }\end{array}$ \\
\hline & $\operatorname{tag} 326$ & 2 & 1 & 3 & PB000422.00.0 & & $d, I, P$ & PF07_0I26 & \\
\hline & $\operatorname{tag} 213$ & 0 & 3 & 3 & PB000468.02.0 & SIS9 & $\Delta, \mathrm{l}$ & PFL0335c & $\begin{array}{l}\text { Eukaryotic translation initiation } \\
\text { factor } 5\end{array}$ \\
\hline & $\operatorname{tag} 197$ & 0 & 3 & 3 & PB000626.00.0 & & $d, I$ & PFI4_0224 & $\begin{array}{l}\text { PPI-like protein serine/threonine } \\
\text { phosphatase }\end{array}$ \\
\hline & $\operatorname{tag} 68$ & I & 2 & 3 & PB000674.01.0 & SISIO & $\Delta, \mathrm{I}, \mathrm{P}$ & PFI3_0058 & RNA recognition motif \\
\hline & $\operatorname{tag} 170$ & 0 & 3 & 3 & PB000876.00.0 & & $\mathrm{Pb}, \mathrm{I}, \mathrm{P}$ & MAL8PI.78 & Small heat shock protein \\
\hline & $\operatorname{tag} 236$ & 0 & 3 & 3 & PB000892.00.0 & Pbs 36 & $\Delta, \mathrm{I}$ & PFD0210c & Pbs36, Sexual stage antigen, PS \\
\hline & $\operatorname{tag} 20$ & 0 & 3 & 3 & PB000911.00.0* & SISII & $\Delta, \mathrm{l}$ & PFE0965c & Vacuolar ATP synthetase, 4 TM \\
\hline & $\operatorname{tag} 8$ & I & 2 & 3 & PBO0II I01.02.0 & $S I S I 2$ & $\Delta \Delta$ & PFI4_0395 & \\
\hline & $\operatorname{tag} 119$ & 0 & 3 & 3 & PB00II 43.02 .0 & SISI3 & $\Delta, \mathrm{I}, \mathrm{P}$ & PFI4_0083 & Ribosomal protein S8e \\
\hline & $\operatorname{tag} 122$ & I & 2 & 3 & PBO0I 247.02.0 & $\mathrm{S} / 4$ & $\mathrm{~d}, \mathrm{I}, \mathrm{P}$ & PFL0370w & \\
\hline & $\operatorname{tag} 127$ & 0 & 3 & 3 & PB00I432.02.0 & SISI4 & $\Delta, \mathrm{l}$ & PFE0340c & Peptidase S54, rhomboid, 7 TM \\
\hline & tag 155 & 3 & 0 & 3 & PB00I575.02.0 & SISI5 & $\Delta, \mathrm{I}$ & PFB0270w & $\begin{array}{l}\text { SP, TM, Fe-S metabolism associated } \\
\text { domain }\end{array}$ \\
\hline & $\operatorname{tag} 150$ & 0 & 3 & 3 & PBI04I65.00.0 & & $d, I$ & PFI0675w & \\
\hline & $\operatorname{tag} 305$ & 0 & 3 & 3 & PBI0446I.00.0 & & d & -- & SP, TM \\
\hline
\end{tabular}


Table I: List of I 23 genes identified by SAGE in P. berghei salivary gland sporozoites (Continued)

\begin{tabular}{|c|c|c|c|c|c|c|c|c|}
\hline $\operatorname{tag} 350$ & 0 & 3 & 3 & PBI05607.00.0 & & d & -- & 2 TM \\
\hline $\operatorname{tag} 106$ & 1 & 2 & 3 & PBI05732.00.0 & & d & -- & TM \\
\hline $\operatorname{tag} 196$ & 0 & 3 & 3 & PBI06033.00.0 & SISI 6 & $\Delta, \mathrm{I}$ & PFI0_0296 & \\
\hline $\operatorname{tag} 4 \mathrm{I}$ & I & 2 & 3 & PBI07193.00.0* & SISI 7 & $\Delta \Delta$ & PFFII95c & \\
\hline $\operatorname{tag} 121$ & I & 2 & 3 & PBI08098.00.0 & & $d$ & -- & TM \\
\hline tag 157 & 2 & 1 & 3 & PB300784.00.0 & & $d, I$ & MAL8PI.I54 & \\
\hline $\operatorname{tag} 362$ & 0 & 2 & 2 & PYOI277** & SISI 8 & $\Delta \Delta$ & PFL2080c & \\
\hline tag 142 & 0 & 2 & 2 & PB000006.00.0 & SISIO & $\Delta, \mathrm{I}$ & PFE0995c & \\
\hline $\operatorname{tag} 265$ & 0 & 2 & 2 & PB000064.03.0 & SIS20 & $\Delta \Delta$ & PFB05IOw & 3 TM \\
\hline tag 143 & 0 & 2 & 2 & PB000092.02.0 & UIS2 & $a, I, P$ & PFI4_06|4 & \\
\hline tag 355 & I & 1 & 2 & PB000094.03.0 & SIS2I & $\Delta, \mathrm{I}, \mathrm{P}$ & MALI 2 PI.I80 & Arginyl-tRNA synthetase \\
\hline $\operatorname{tag} 15$ & I & I & 2 & PB0001II.01.0 & & $d, I, P$ & MALI2PI.63 & \\
\hline $\operatorname{tag} 57$ & I & 1 & 2 & PB000I20.01.0 & SIS22 & $\Delta, \mathrm{P}$ & PFCI065w & \\
\hline $\operatorname{tag} 26$ & I & 1 & 2 & PB000I33.00.0 & SIS23 & $\Delta$ & -- & \\
\hline $\operatorname{tag} 59$ & 0 & 2 & 2 & PB000171.01.0 & SIS24 & $\Delta$ & -- & \\
\hline tag 339 & 0 & 2 & 2 & PB000I78.02.0 & SIS 25 & $\Delta, \mathrm{I}$ & PFE08I0c & $40 \mathrm{~S}$ ribosomal subunit protein $\mathrm{SI} 4$ \\
\hline $\operatorname{tag} 139$ & 0 & 2 & 2 & PB000207.01.0 & SIS26 & $\Delta, \mathrm{I}$ & PFLI050w & SP, TRAF-like \\
\hline $\operatorname{tag} 221$ & 0 & 2 & 2 & PB000297.0I.0 & SIS27 & $\Delta, \mathrm{l}$ & PFII_025I & $\begin{array}{l}\text { SP, Endoplasmic reticulum } \\
\text { oxidoreductin }\end{array}$ \\
\hline $\operatorname{tag} 12$ & 0 & 2 & 2 & PB000307.01.0 & UIS9-7 & $\mathrm{a}, \mathrm{I}$ & PFE0935c & RNA-binding protein \\
\hline $\operatorname{tag} 134$ & 0 & 2 & 2 & PB000352.00.0 & SIS28 & $\Delta, \mathrm{l}$ & PFII_0I50 & $\begin{array}{l}\text { SP, } 6 \mathrm{TM} \text {, Rhomboid family, SecY } \\
\text { protein }\end{array}$ \\
\hline $\operatorname{tag} 51$ & 2 & 0 & 2 & PB000352.02.0 & & $d, I, P$ & PFL2440w & DNA repair protein rhpl6 \\
\hline $\operatorname{tag} 317$ & I & I & 2 & PB000354.03.0 & & $\mathrm{d}, \mathrm{I}$ & PFI0_0283 & TM \\
\hline tag 285 & 0 & 2 & 2 & PB000396.01.0 & SIS29 & $\Delta, \mathrm{I}$ & PFC0330w & PDZ domain protein \\
\hline $\operatorname{tag} 292$ & 0 & 2 & 2 & PB0004I 2.02 .0 & SIS30 & $\Delta, \mathrm{I}$ & PFI0750c & \\
\hline $\operatorname{tag} 17$ & 0 & 2 & 2 & PB000424.02.0 & & $d, 1$ & PFII_0358 & $\begin{array}{l}\text { DNA-directed RNA polymerase, } \\
\text { beta subunit }\end{array}$ \\
\hline $\operatorname{tag} 320$ & 0 & 2 & 2 & PB000450.03.0 & SIS3I & $\Delta, \mathrm{I}$ & MALI3PI.| 48 & myosin \\
\hline tag 54 & 0 & 2 & 2 & PB000530.00.0 & & d, I & PFE0400w & ankyrin \\
\hline tag 277 & 0 & 2 & 2 & PB000553.03.0 & & d, I & PFI3_016I & \\
\hline tag 303 & 1 & 1 & 2 & PB000591.00.0 & SIS32 & $\Delta \Delta$ & PFC0I25w & DNAJ domain protein \\
\hline $\operatorname{tag} 184$ & 0 & 2 & 2 & PB000599.03.0 & SIS33 & $\Delta, \mathrm{I}$ & PFI4_068I & Diacylglycerol kinase \\
\hline $\operatorname{tag} 34$ & 0 & 2 & 2 & PB000604.01.0 & & d & PFF0840w & \\
\hline $\operatorname{tag} 87$ & 0 & 2 & 2 & PB000610.02.0 & SIS34 & $\Delta, \mathrm{I}$ & PFL2390c & \\
\hline tag 204 & 0 & 2 & 2 & PB000624.01.0 & SIS35 & $\Delta, \mathrm{l}$ & PFI3_026I & ATP binding protein \\
\hline $\operatorname{tag} 128$ & 0 & 2 & 2 & PB000650.00.0 & SIS36 & $\Delta, \mathrm{I}, \mathrm{P}$ & PFI4_0446 & Fasciclin domain \\
\hline tag 58 & 0 & 2 & 2 & PB000675.02.0 & SIS37 & $\Delta \Delta$ & PFFI450w & Secl4-like cytosolic factor \\
\hline tag 144 & I & 1 & 2 & PB000709.00.0 & SIS38 & $\Delta, \mathrm{l}$ & PFI4_0I8I & Calmodulin \\
\hline tag 289 & 2 & 0 & 2 & PB000798.02.0 & MAEBL & $d, I, P$ & PFII_0486 & MAEBL, SP, TM \\
\hline $\operatorname{tag} 88$ & 0 & 2 & 2 & PB000807.0I.0 & SIS39 & $\Delta, \mathrm{I}$ & PFD0485w & Ferlin like protein \\
\hline $\operatorname{tag} 353$ & 0 & 2 & 2 & PB0008II.01.0 & & $d, I$ & MAL7PI.I25 & \\
\hline $\operatorname{tag} 80$ & 1 & 1 & 2 & PB000837.02.0 & SIS40 & $\Delta, \mathrm{I}$ & PFI4_0695 & $\begin{array}{l}\text { DNA-directed RNA polymerase, } \\
\text { alpha subunit }\end{array}$ \\
\hline $\operatorname{tag} 116$ & 0 & 2 & 2 & PB000857.0I.0 & SIS4I & $\Delta, \mathrm{I}, \mathrm{P}$ & PFII_0I83 & GTP-binding nuclear protein ran/tc4 \\
\hline $\operatorname{tag} 238$ & 0 & 2 & 2 & PB000874.02.0 & SIS42 & $\Delta, \mathrm{l}$ & MAL8PI.I42 & Proteasome beta-subunit \\
\hline $\operatorname{tag} 79$ & 0 & 2 & 2 & PB000903.01.0 & SIS43 & $\Delta, \mathrm{I}$ & PFII_0I97 & SP, Ankyrin repeat \\
\hline tag 227 & 0 & 2 & 2 & PB000904.0I.0 & SIS44 & $\Delta, \mathrm{I}$ & PFII_0I96 & $\mathrm{SP}$ \\
\hline tag 206 & 0 & 2 & 2 & PB000927.03.0 & SIS45 & $\Delta, \mathrm{I}$ & MALI2PI.II3 & $\begin{array}{l}\text { Heat shock protein DNAJ } \\
\text { homologue Pfj4 }\end{array}$ \\
\hline $\operatorname{tag} 210$ & 0 & 2 & 2 & PB000941.01.0 & SIS46 & $\Delta, \mathrm{I}$ & PFI0_0096 & Octapeptide repeat \\
\hline tag 349 & 0 & 2 & 2 & PB000994.02.0* & & d, I & PFLI690w & \\
\hline $\operatorname{tag} 218$ & 0 & 2 & 2 & PB00I066.02.0 & & $d, I$ & PFIO_0I40 & SPRY \\
\hline tag 228 & 0 & 2 & 2 & PBO0I080.02.0 & SIS47 & $\Delta, \mathrm{I}$ & PFL0870w & $\begin{array}{l}\text { SP, TM, TSP, thrombospondin- } \\
\text { related } 3\end{array}$ \\
\hline $\operatorname{tag} 267$ & I & I & 2 & PB00III8.02.0 & UIS4-6 & $d, I$ & PFA0I70c & $\mathrm{TM}$ \\
\hline $\operatorname{tag} 27$ & 0 & 2 & 2 & PBO0II 20.00 .0 & SIS48 & $\Delta, \mathrm{l}$ & MALI3PI.I50 & $2 \mathrm{TM}$ \\
\hline $\operatorname{tag} 6$ & 0 & 2 & 2 & PBO0II 30.00 .0 & SIS49 & $\Delta, \mathrm{I}, \mathrm{P}$ & MAL8PI.I33 & $\begin{array}{l}\text { Glycosyltransferase family } 28 \\
\text { protein }\end{array}$ \\
\hline $\operatorname{tag} 124$ & 1 & 1 & 2 & PB00II57.02.0 & SIS50 & $\Delta, \mathrm{I}$ & MAL8PI.67 & PIN domain like \\
\hline $\operatorname{tag} 301$ & 0 & 2 & 2 & PB00II 78.02 .0 & SIS5I & $\Delta, \mathrm{I}$ & PFD0300w & \\
\hline $\operatorname{tag} 123$ & 0 & 2 & 2 & PBO0I 253.00 .0 & SIS52 & $\Delta, \mathrm{l}$ & PFD0360w & Zinc finger \\
\hline $\operatorname{tag} 331$ & 0 & 2 & 2 & PB00I305.00.0 & SIS53 & $\Delta, \mathrm{I}, \mathrm{P}$ & PFII_0I68 & Serine esterase \\
\hline
\end{tabular}


Table I: List of I 23 genes identified by SAGE in P. berghei salivary gland sporozoites (Continued)

\begin{tabular}{|c|c|c|c|c|c|c|c|c|}
\hline $\operatorname{tag} 70$ & $T$ & $T$ & 2 & PB001374.02.0 & & $d, I, P$ & MALI3PI.304 & $\begin{array}{l}\text { Malaria antigen, } \\
\text { metalloendopeptidase }\end{array}$ \\
\hline $\operatorname{tag} 31$ & 0 & 2 & 2 & PB00I507.02.0 & SIS54 & $\Delta \Delta$ & PFB0620w & \\
\hline $\operatorname{tag} 312$ & 0 & 2 & 2 & PB00I5I7.02.0 & & $d$ & PFF0800w & SP, TM, vWFA, TSPI \\
\hline tag 43 & I & I & 2 & PBI0034I.00.0 & SIS55 & $\Delta$ & -- & \\
\hline $\operatorname{tag} 93$ & I & I & 2 & PBI0I083.00.0 & & $d$ & -- & \\
\hline $\operatorname{tag} 61$ & 2 & 0 & 2 & PBI0II 48.00 .0 & SIS56 & $\Delta$ & -- & \\
\hline $\operatorname{tag} 114$ & 2 & 0 & 2 & PBI0|408.00.0 & SIS57 & $\Delta, \mathrm{I}$ & PFEI $260 c$ & TM \\
\hline tag 56 & 2 & 0 & 2 & PBI0I596.00.0 & SIS58 & $\Delta$ & -- & \\
\hline tag 342 & 0 & 2 & 2 & PBI022II.00.0 & SIS59 & $\Delta$ & -- & \\
\hline $\operatorname{tag} 318$ & I & I & 2 & PBI02277.00.0 & & d & -- & \\
\hline $\operatorname{tag} 71$ & 0 & 2 & 2 & PBI03980.00.0 & SIS60 & $\Delta$ & -- & 2 TM \\
\hline $\operatorname{tag} 271$ & 0 & 2 & 2 & PBI05487.00.0 & & $d$ & -- & $2 \mathrm{TM}$ \\
\hline tag 35 & 0 & 2 & 2 & PBI06484.00.0 & SIS6I & $\Delta, \mathrm{I}$ & PFI4_0449 & \\
\hline tag 208 & 0 & 2 & 2 & PBI08086.00.0 & SIS62 & $\Delta$ & -- & \\
\hline $\operatorname{tag}|5|$ & 0 & 2 & 2 & PB0006|8.02.0 & SIS63 & $\Delta$ & PFD0725c & $\begin{array}{l}\text { arsenical pump-driving ATPase, } \\
\text { putative }\end{array}$ \\
\hline tag 179 & I & 1 & 2 & PB300567.00.0 & SIS64 & $\Delta \Delta$ & PFL2420w & \\
\hline tag 85 & 0 & 2 & 2 & PB300953.00.0 & SIS65 & $\Delta \Delta$ & MAL8PI.I2I & \\
\hline $\operatorname{tag} 33$ & I & 1 & 2 & PB30I 273.00.0 & & $d, I$ & PFLI695c & \\
\hline $\operatorname{tag} 47$ & 0 & 2 & 2 & PB000460.0I.0 & SIS66 & $\Delta, \mathrm{I}$ & PFC0750w & SP \\
\hline
\end{tabular}

(a) : mRNA detected in $P$. berghei sporozoites [14].

(d): mRNA detected in $P$. yoelii sporozoites [13].

$\mathrm{Pb}$ : detected by proteomics in $P$. berghei sporozoites [II].

$P$ : detected by proteomics in P. falciparum sporozoites [10].

I : detected in $P$. falciparum sporozoites with microarrays [9].

$\mathrm{SP}$ : signal peptide.

TM : transmembrane domain.

** : orthologue of a $P$. yoelli gene for which a $P$. berghei gene is not yet annotated.

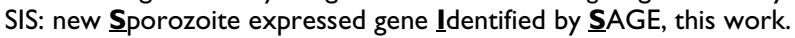

$\Delta$ : no rodent Plasmodium sporozoite ESTs or proteomics data.

$\Delta \Delta$ : no sporozoite ESTs or detection by microarrays or proteomics in Plasmodium species.

dances, we selected eighteen known or novel genes, predicted to be expressed at high or low levels, and quantified their RNA by qPCR in sporozoites isolated from SG at d18 of infection. The values were normalised to the reference gene PB001026.00.0 (CS) and plotted against the number of times the identifying tag was found in the SAGE library at $\mathrm{d} 18$ of infection (Figure 2). A good correlation $\left(\mathrm{R}^{2}=\right.$ $0.8)$ was found and was even greater $\left(R^{2}=0.96\right.$, not shown), when a second abundant tag sequence for two genes, UIS4 and TRAP, was taken into account. Thus, the number of times a tag was found in our SAGE data correctly reflects the gene expression levels in sporozoites.

\section{Hierarchical classification of sporozoite expressed genes}

In Table 1, the 123 genes unambiguously identified by this SAGE as being expressed in SG sporozoites have been classified into three groups according to the number of times the identifying tag sequence was found in the combined $\mathrm{d} 14$ and d 18 libraries (with the caveat that for some genes there may be an underestimation due to the criteria used above).

\section{Group I}

The first group of highly expressed genes, defined by tags found more than 20 times in the combined libraries, con- tains five genes of which four have been described previously: PB000374.03.0, which codes for TRAP, a major sporozoite protein having an essential role in sporozoite motility [22]; PB100551.00.0 and PB107461.00.0, which code for UIS4 and UIS7 respectively, and were identified by SSH as genes whose expression is upregulated in SG sporozoites compared to midgut sporozoites [14]; PB001063.00.0, also known as S23, which codes for a reticulocyte binding protein and was identified by SSH as a gene upregulated in SG sporozoites compared to blood stages [15].

Surprisingly, the gene PB402615.00.0, for which the identifying tag (tag 335) was found the most often, has not been described previously. The gene sequence aligns with numerous ESTs of $P$. yoelii sporozoites and parasites developing in the absence of host cells $[13,23]$. To further characterize the gene structure, a manual clustering of these ESTs was performed. Several tags were found along this cluster, both in sense and antisense orientations and, as expected, the most 3 ' tag was also the most abundant (Figure $3 \mathrm{~A}$ ). The other internal tags, one of which is highly represented (tag 189, see additional file 1), may be due to either alternative polyadenylation events or priming at internal polyA stretches during cDNA synthesis, as 


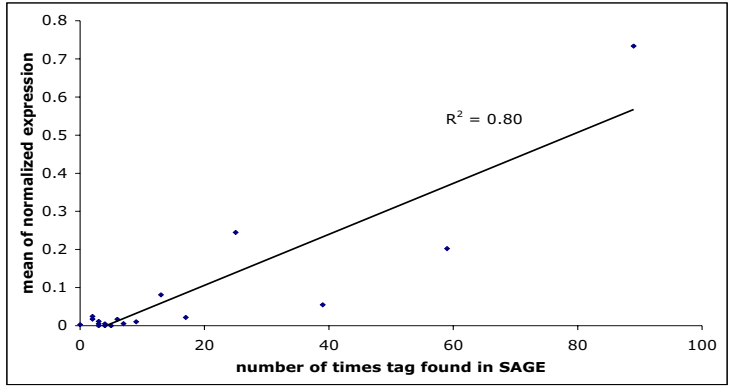

Figure 2

Correlation between the levels of gene expression as determined by QPCR and the number of times the identifying tag sequence was found in the SAGE library. $R^{2}$ is the coefficient of correlation.

hypothesized by others [24]. To rule out the possibility that the cluster covers two different genes, a RT-PCR was performed using primers at the $5^{\prime}$ and 3 ' end of the cluster and this detected a unique transcript of the predicted size (data not shown). Based on our results and annotation, we propose that the ORF predicted for PB402615.00.0 during automatic annotation is incorrect and that this gene codes for a $17 \mathrm{KDa}$ protein, rich in tyrosine and basic amino acids. Furthermore, this new annotation indicates that there are orthologous sequences in $P$. yoelii (PY02432), P. chabaudi (PC400629.00.0) and also in $P$. falciparum (PFgenefinder_63r.) (Figure 3B).

Interestingly, PB402615.00.0 is not the only gene characterized by several abundant tags. For instance, two tags are characteristic of PB100551.00.0, encoding UIS4: the most abundant (tag 186, found 95 times) is located at the end of the ORF, while the other (tag 153, found 74 times), is located $650 \mathrm{nt}$ downstream and probably defines a transcript with a longer 3' UTR. Such observations may be useful when defining the gene structure with the complete potential regulatory sequences.

\section{Group 2}

The second group contains eight moderately expressed genes defined by tags found 10 to 20 times. Among these, there is one UIS gene (UIS10/PB000484.00.0) and three $S$ genes S13/SPECT2 (PB000252.01.0), S21/PbTRSP (PB000881.01.0) and S12 (PB104017.00.0). UIS10/PbPL codes for a lecithine-cholesterol acyl-transferase involved in cell traversal [25]. The S13/SPECT2 protein is characterized by a MAC/Perforin domain and was found to be essential for membrane attack during cell invasion [26]. The protein S21/PbTRSP, which contains a thrombospondin type 1 domain, has recently been shown to have a role in host cell invasion [27]. Finally, S12 codes for a protein with a predicted signal peptide, but whose function has yet to be characterized.

The gene PB000649.01.0 codes for the cysteine protease ECP1, involved in egress of sporozoites from oocysts [28]. Two genes, PB000891.00.0 (Pbs36p) and PB000400.01.0, encode potential GPI- anchored proteins of the Pfs $48 / 45$ family, orthologues of P. falciparum Pf52 and Pfs 38 proteins [29]. Proteins of this family, characterized by a 6-Cys domain, are involved in intra-hepatic development and/ or gametocyte fertilization [21,30,31]. Pfs38 expression was previously observed in $P$. falciparum sporozoites [9] but not in rodent sporozoites. We have named PB000400.01.0, SIS1, for Sporozoite expressed gene Identified by $\underline{\text { SAGE} 1 ~(s e e ~ T a b l e ~ 1) . ~ F i n a l l y, ~ P B 000317.00 .0, ~}$ whose structure has been manually revised, codes for a potential secreted and GPI-anchored protein and therefore constitutes a novel candidate that could be involved in host cell recognition/invasion.

\section{Group 3}

Of the remaining 110 genes, expressed at low levels and defined by tags found less than ten times, 43 aligned with $P$. yoelii or $P$. berghei sporozoite ESTs, one was detected in P. berghei sporozoites by proteomics and PB000892.00.0/ Pbs36 has been described in sporozoites [21]. Thus 65 genes in this group are shown for the first time to be expressed in this stage of the P. berghei parasite (indicated as SIS2-66 on Table 1). Orthologous P. falciparum genes are predicted for 90 genes in this group, and expression in sporozoites has been detected for 74 by microarrays (of which 20 also by proteomics) and one by proteomics only. The 20 P. berghei predicted genes for which there are no obvious $P$. falciparum orthologues could correspond to incomplete genes and require more precise annotation. Alternatively, they may be highly divergent genes or genes whose prediction has been missed during $P$. falciparum genome annotation.

Nine genes in this group have been described previously: AB125370 (SPECT) and PB000892.00.0 (encoding Pbs36) are important for liver infectivity $[21,32]$ and PB000798.02.0, encoding MAEBL, has a role in the initial binding of sporozoites to the mosquito SG [33]. Six genes, UIS1, UIS2, UIS9-7/UIS29-1, UIS4-6, S25, S14, were already identified as being expressed in SG sporozoites $[14,15]$.

In addition, two other genes could have a potential role in adhesion/invasion of host cells: PB001517.02.0 codes for a protein with a Thrombospondin 1 domain and a vonWillebrand type A domain, and PB001080.02.0, which encodes a protein defined as thrombospondin-related 3 (also found as AF375983 in Genbank). Proteins involved 
A

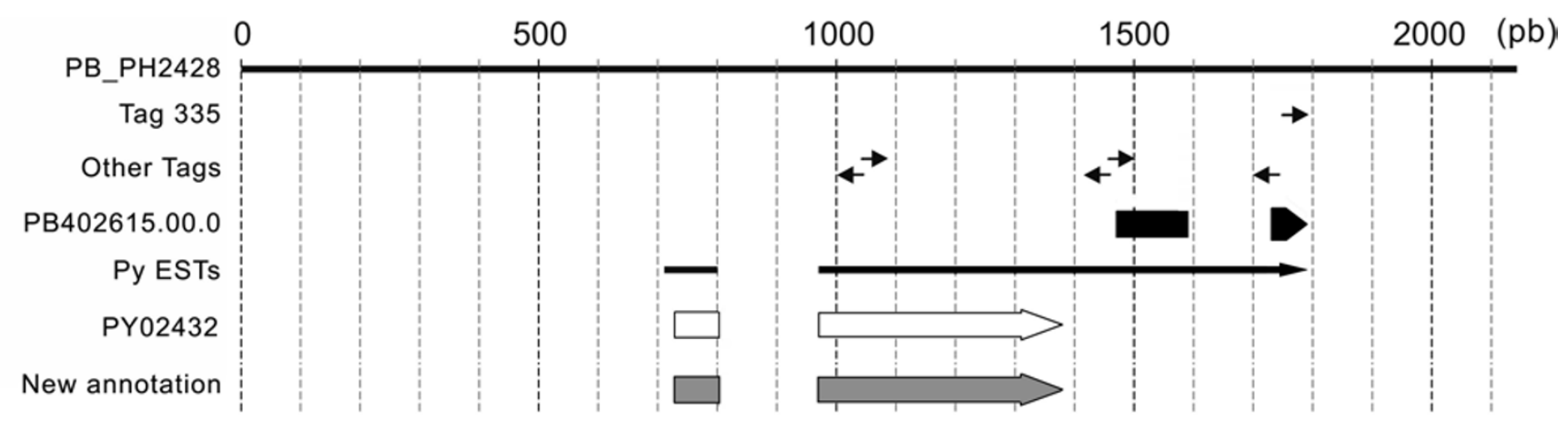

B

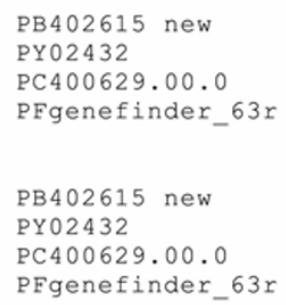

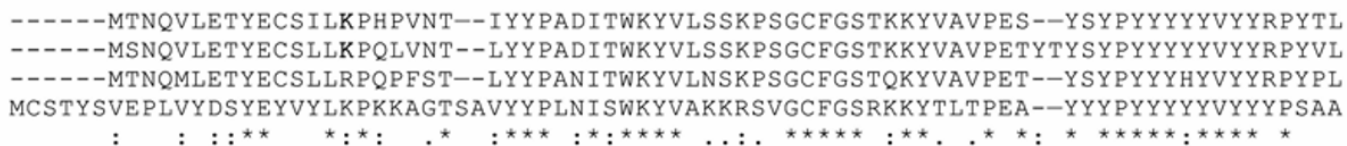

GNITLS IKNADKSKKKVNESNDQEKKEESNDENGTKTSKKNDECNDRENNTKKYVSVLTPPYYIGSLFYP--TAIFYP GNVTLS I KNADQSKKKVNELNNQEKKEEPSDENGSKTSKKNDECNDRENNTKKYVS ILTPPYYIGSLFYP--TAIVFP AN I TLS I KHE DKNKKKVNE LNNQEKKEELNDEDESKT SKKNNECNDKENNTKKYVSVVSP PYY IGSLYYP--TAI FYP R-----LVRTTRKEKVLKENNNKESEDE-NKQDNVGTEKKECDCSEKEKYIPTYVPLTESYYFPPSALYVPHYSVLVP

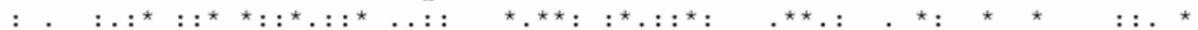

\section{Figure 3}

New annotation of PB402615.00.0. A) Continuous black line corresponds to the $P$. berghei genomic DNA contig; the position of tags are indicated by small arrows ( $\rightarrow$ : sense tag); ( $\leftarrow$ : antisense tag); thick black arrow: PB4026I5.00.0 as annotated in PlasmoDB; thin black arrow: EST cluster; thick white arrow: ORF of $P$. yoelii orthologue; thick grey arrow: new annotation of PB402615.00.0 ORF. B) Alignement of protein sequences of PB4026I5.00.0 orthologues in P. yoelii, P. chabaudi and P. falciparum.

in the molecular motor needed for sporozoite motility are also represented by aldolase (PB000757.02.0), which provides the link between TRAP and myosinA [34,35], and by a kinesin-related protein (PB000464.00.0/S25). While myosinA, which is thought to play a major role in the motility of Apicomplexa zoites, is absent from our description (with a tag found only once), another gene encoding a potential myosin is identified (PB000450.03.0). Two genes encoding proteases of the rhomboid family (PB001432.02.0/SIS14 and PB000352.00.0/SIS28) are also found. Interestingly, these proteins are the orthologues of PfROM4 and PfROM1, respectively, which are able to cleave adhesins, such as TRAP, AMA1, MAEBL and others, that are involved in interactions with host-cell receptors [36].

The expression of only two genes encoding ribosomal proteins has been detected, confirming, as previously reported [13], their under-representation in the sporozoite transcriptome. Interestingly, two genes coding for proteins with RNA-binding domains are identified, one of which has a pumilio domain suggesting a role in the negative regulation of translation [37]. These proteins were previously described as being upregulated in P. falciparum gametocytes and sporozoites [9] and may be involved in the regulation of sporozoite protein expression.

Other genes found in this group code for proteins with diverse biological functions for example energy metabolism, signal transduction and protein modification. Interestingly, a gene encoding a putative sugar transporter (PB000161.03.0), whose P. falciparum orthologue is expressed specifically in sporozoites, is present [9]. We previously reported an increase in mRNA levels of an Anopheles sugar transporter in infected SG [16]. These two transporters may play a role in providing the sporozoite with sufficient energy resources for its journey from the oocysts to the SG and from the bite site to the liver in the vertebrate host. The presence of three genes coding for proteins involved in iron-sulphur cluster formation and iron homeostasis can also be noted. Iron-sulphur cluster formation is essential for a wide variety of processes, including facilitation of electron transfer in oxidative phosphorylation and enzymatic activities in mitochondria, cytoplasm or nucleus as well as sensing of intracellular iron and/or oxidant levels. Expression of these genes 
may be preparing the sporozoite for high mitochondrial activities related to motility and/or for the future iron-rich blood environment.

\section{Expression profiles of sporozoite expressed genes}

To further characterize a number of genes that were not previously studied, namely PB402615.00.0 (group1), PB000317.00.0 and PB000400.01.0 (group2), PB001080.02.0 (Thrombospondin-related 3 protein), PB000757.02.0 (aldolase), PB001432.02.0 (rhomboid protein), PB000787.03.0 (arginase), PB000468.02.0 (eukaryotic translation initiation factor 5) and PB000675.02.0 (sec14-like protein) (group 3), we compared their expression profiles with those of known transcripts such as CS, UIS1, UIS3, UIS4, UIS7, TRAP, S23, Pbs36, Pbs36p, MAEBL and SPECT2. The RNA levels were quantified by qPCR in ookinetes, midgut and SG sporozoites and blood stages and the results were normalised with respect to $h s p 70$ which is expressed at all stages (Figure 4).

All genes showed higher levels of expression in midgut and/or SG sporozoites compared to ookinete or blood stages, with the exception of PB000787.03.0 whose expression is clearly not sporozoite specific. Other genes, for example PB000400.01.0, PB000757.02.0 and PB001432.02.0 are easily detectable in blood stages, suggesting they may also have a role at this stage. Finally, PB001432.02.0, PB000317.00.0, PB001080.02.0 and PB000400.01.0 are expressed, like CS, at relatively high levels in the ookinete stage, although this does not mean that the protein is produced.

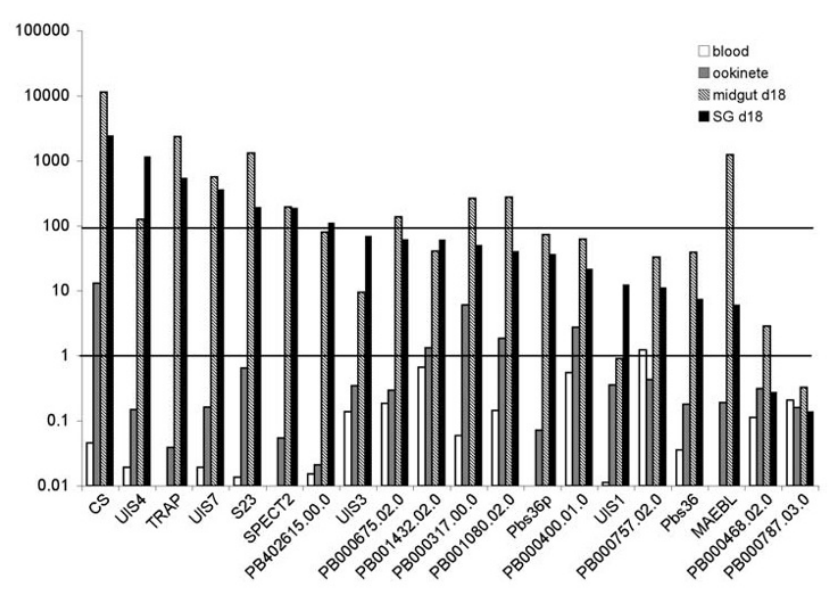

\section{Figure 4}

Histogram representation of qPCR analysis of gene expression in mixed blood stages, ookinetes, d 8 midgut sporozoites and $\mathrm{d} I 8$ salivary gland sporozoites. $X$ axis: genes tested; $Y$ axis: log scale of mean normalised expression.
As observed in Table 1, the number of times a tag is found in the SG libraries at $\mathrm{d} 18$ of infection often differs to that at $\mathrm{d} 14$. This is due in part to the higher number of tags sequenced in the $\mathrm{d} 18$ library ( 2 fold) and to the increase ( 2 fold) in the number of sporozoites inside the glands at d18. However, the tags of some genes, for example UIS4, increase up to 15 fold between $\mathrm{d} 14$ and $\mathrm{d} 18$ whereas they decrease for others. This suggested that there might be variations in gene expression during sporozoite storage in the glands. To further characterize these variations, the relative levels of gene expression for the same panel of genes as above were determined in sporozoites isolated from SG and midguts of A. gambiae mosquitoes at $\mathrm{d} 14$ or $\mathrm{d} 18$ of infection. The values were calculated from the geometric averages and normalised to the geometric mean of PB001026.00.0 (CS), as this gene was determined to be the best reference using GeNORM software.

The results show important increases (4-66 times) in RNA amounts in SG compared to midgut sporozoites for UIS4, UIS1, UIS3, SPECT2, UIS7 and PB402615.00.0 at $\mathrm{d} 18$ (see Table 2). These results were expected for the UIS genes as they were found in an SSH library between SG and midgut sporozoites [14]. They also suggest that PB402615.00.0 may be important for preparing the sporozoites for infection. On the contrary, there is significantly less MAEBL RNA in SG compared to midgut sporozoites in agreement with MAEBL having a role in sporozoite adhesion to mosquito salivary glands [33].

In addition, the ratios obtained between $\mathrm{d} 18$ and $\mathrm{d} 14$ SG sporozoites indicate that there is a significant increase in expression over this period for UIS4, UIS1, UIS3 and UIS7, whereas there is no substantial change in RNA quantities for the other genes. Similar increases in expression were also seen for UIS3 and UIS4 in A. stephensi infected salivary glands suggesting that $P$. berghei sporozoites develop similarly in A. gambiae and A. stephensi (not shown).

Taken together, the qPCR data show that sporozoites are capable of modulating their RNA amounts between the midgut and salivary glands, as well as during their storage within the latter.

\section{Discussion}

Although the transcriptional repertoire of Plasmodium sporozoites has been investigated in several laboratories using different techniques, including cDNA libraries, $\mathrm{SSH}$, microarrays and proteomics, only the microarray data has provided information concerning the level of gene expression [9]. We have obtained new data concerning the transcriptional repertoire of $P$. berghei sporozoites using SAGE on A. gambiae infected salivary glands. SAGE does not require a priori knowledge of the sequence of genes to be 
Table 2: Variation of gene expression in P. berghei sporozoites developping in A. gambiae.

\begin{tabular}{|c|c|c|c|c|c|}
\hline \multirow[b]{2}{*}{ Gene ID } & \multirow[b]{2}{*}{ Gene name } & \multicolumn{2}{|c|}{ between tissues } & \multicolumn{2}{|c|}{ with time } \\
\hline & & ratios at d I 4 SG/midgut & ratios at d I 8 SG/midgut & ratio SG d I 8/d I 4 & ratio midgut $\mathrm{d} / 8 / \mathrm{d} / 4$ \\
\hline PBI0055I.00.0 & UIS4 & $37.07 *$ & $66.31 * *$ & $4.17^{*}$ & $2.33^{*}$ \\
\hline PBI08190.00.0 & UISI & $20.72^{*}$ & $56.52^{* *}$ & $2.15^{*}$ & $0.79 *$ \\
\hline РB000892.03.0 & UIS3 & $20.88^{*}$ & $54.45^{* *}$ & $3.77^{*}$ & $1.45^{*}$ \\
\hline PB4026।5.00.0 & & $8.22 *$ & $10.67^{* *}$ & $1.57^{*}$ & $1.21 *$ \\
\hline PB000252.0I.0 & SPECT2 & $7.55^{*}$ & $7.69 * *$ & $1.24 *$ & $1.22 *$ \\
\hline PBI 07461.00 .0 & UIS7 & $5.81 *$ & $4.59 * *$ & $2.55^{*}$ & $3.24 *$ \\
\hline РB000891.00.0 & Pbs36p & $4.67^{*}$ & $3.79 * *$ & $0.77^{*}$ & $0.95^{*}$ \\
\hline PB000787.03.0 & & $1.13^{*}$ & $2.32 * *$ & $1.54^{*}$ & $0.75 *$ \\
\hline PB000675.02.0 & & $2.50 *$ & $2.13^{* *}$ & $0.76^{*}$ & $0.90 *$ \\
\hline PB000400.01.0 & & $7.52 *$ & $1.97 * *$ & $0.49 *$ & $1.88 *$ \\
\hline РB000892.00.0 & Pbs36 & $1.54 *$ & $1.89 * *$ & $1.28 *$ & $1.04^{*}$ \\
\hline PB000374.03.0 & TRAP & $1.57 *$ & $1.88^{* *}$ & $1.22 *$ & $1.01 *$ \\
\hline РВ000757.02.0 & & I.7I* & $1.64^{* *}$ & $0.7 I^{*}$ & $0.74 *$ \\
\hline PB00I432.02.0 & & $1.54 *$ & $1.35^{* *}$ & $0.75^{*}$ & $0.86^{*}$ \\
\hline PB00I063.00.0 & $S 23$ & $1.76 *$ & $1.00 * *$ & $0.80 *$ & $1.4 I^{*}$ \\
\hline PB0003 I7.00.0 & & $1.12^{*}$ & $0.87^{* *}$ & $0.77^{*}$ & $0.99 *$ \\
\hline PB00I080.02.0 & & $1.20 *$ & $0.70 * *$ & $0.75^{*}$ & $1.29 *$ \\
\hline РВ000468.02.0 & & $0.52 *$ & $0.44^{* *}$ & $0.90 *$ & $1.05^{*}$ \\
\hline РB000798.02.0 & MAEBL & $0.04 *$ & $0.04^{* *}$ & $0.87 *$ & $0.87^{*}$ \\
\hline
\end{tabular}

$*: p=0.05 * *: p=0.01$

analysed and provides quantification of gene expression by the number of times a tag sequence is obtained [17]. However, since the sequence and annotation of the $P$. berghei genome is incomplete, the attribution of a tag sequence to a gene was not straightforward.

Several criteria were applied before retaining a tag sequence as a gene identifier: it was found twice or more in the cumulative SAGE libraries, the BLASTN analysis gave a unique hit in the genome, which was in the sense orientation of an annotated gene and was located at the most 3' predicted NlaIII site or within $500 \mathrm{nt}$ of the stop codon of a neighbouring gene. These combined criteria resulted in the unambiguous identification of 123 genes expressed in SG sporozoites, of which 16 were already known to be sporozoite-expressed genes: TRAP, several UIS and $S$ genes, SPECT, Pbs36p, Pbs36 and MAEBL. It should be noted that this list of 123 P. berghei SG sporozoite-expressed genes is not exhaustive.

Of the 2154 unique tag sequences found at least twice in the libraries from infected mosquitoes, only 25\% (530) matched perfectly to the present version of the $P$. berghei genome. The 1624 remaining tags may derive from $A$. gambiae cDNAs. Indeed, 587 match on A. gambiae ESTs and 943 on the A. gambiae genome (see Additional file 1, sheet 2). Alternatively, they may derive from genes not yet sequenced in the $P$. berghei genome. In addition, the absence of matches of some tags could be due to polymorphisms between the P. berghei strain sequenced, ANKA, and the NK65 strain used in our SAGE.

Also, 202 (55\%) of the tag sequences that gave a single hit in the P. berghei genome were not found within an annotated gene. Upon more detailed analysis of their position in the contigs, 63 were found to be within $500 \mathrm{nt}$ of the stop codon of an annotated gene, in the sense orientation and were considered to derive from transcripts of these genes. However, we were unable to place 139 tag sequences either within an annotated ORF or within 500 nt of a stop codon. These tags should help in refining the present annotation of the $P$. berghei genome and may, in the future, be formally proven as corresponding to sporozoite-expressed genes.

Among the 368 tag sequences that gave a single match in the P. berghei genome, 64 were found in the antisense orientation, either within annotated genes (56) or within $500 \mathrm{nt}$ of the stop codon of an annotated gene (8). Antisense RNAs have been described previously in $P$. falciparum and they are suggested to be involved in transcriptional regulation [38-40]. At the present time, there is insufficient $P$. berghei cDNA data and no microarrays using sense and antisense probes, to establish whether or not these tags correspond to antisense RNAs or to transcripts from a gene on the opposite strand. 
The stringent criteria described above resulted in the elimination of the vast majority of tag sequences, retaining $0.7 \%(123 / 17181)$ of the unique tag sequences found only in the infected libraries, representing 3\% (668/ 21721) abundance. Among the tag sequences rejected there are a number that matched with genes known to be expressed in sporozoites, such as CS, UIS3, RON4 and AMA-1. Consequently, other genes expressed in sporozoites may have been eliminated. Furthermore, due to the SAGE cloning procedure, genes for which the transcripts have no NlaIII site will also be missing. The data supplied in the supplemental tables should be useful to other researchers interested in genes expressed in sporozoites.

Amongst the P. berghei SIS genes identified in this study as being expressed in sporozoites, eighteen are predicted to encode proteins with one or more transmembrane regions and/or a signal peptide sequence, suggesting that they are membrane associated or secreted proteins. Other genes of potential interest are PB000464.00.0/S25, a kinesin-related protein, which could be involved in motility; PB000416.02.0, a putative RNA-binding protein of the pumilio/mpt5 family known for their role in repression of gene expression; PB000903.01.0/SIS43 which contains an ankyrin repeat suggesting a role in proteinprotein interaction; PB000650.00.0/SIS36, which contains a fasciclin domain, may have a role in cell adhesion. Finally, PB402615.00.0, for which the identifying tag was the most abundant in this SAGE analysis, is annotated as a hypothetical protein and aligns with $P$. yoelii ESTs from sporozoites as well as parasites developing in the absence of host cells. Our qPCR data show that this gene is expressed in sporozoites but not in ookinetes or blood stages and that there is a substantial increase in the amount of RNA for this gene between midgut and salivary gland sporozoites. This differential regulation between organs and the mRNA abundance in SG suggest a role for this gene in sporozoite infectivity in the mammalian host.

Several properties (motility, infectivity, etc) differ between midgut and SG sporozoites, but it is not known whether these developmental changes are time and/or tissue dependent nor which signalling factors are involved. Interestingly, the qPCR data presented here indicate that, at least for UIS3 and UIS4, not only the tissue (midgut versus salivary gland) but also the time spent in the SG significantly influences the level of expression of individual genes. This change in expression of genes that are essential for development in the liver, is in agreement with the increase in infectivity of SG sporozoites between $\mathrm{d} 14$ and d18 post blood meal [41].

Since SAGE provides a quantitative read out of gene expression, and as our qPCR analysis confirmed this, the 123 genes were classified into 3 groups according to the number of times the tag was found in the libraries. Among the thirteen genes presenting the most abundant tags (groups 1 and 2), there are seven, UIS4, TRAP, S13/ SPECT2, S21/Pb TRSP, ECP1, UIS10/Pb PL, and Pbs36p, that have been shown via gene knockout experiments to be essential for the sporozoite or liver stage development $[7,21,22,25-28]$. Furthermore, among the genes with less abundant tags there are three, SPECT, Pbs36 and MAEBL, which have also been shown to have essential roles $[21,32,33]$. This indicates that our approach has identified several genes known to be essential for sporozoites and points to additional genes that may be required at this stage. It will be of interest to inactivate the novel sporozoite-expressed genes identified in this paper to define their function in the parasite. Mutants that are defective in their development in the mammalian host would be of particular interest as they could provide new tools to probe the host immune response to Plasmodium infection.

\section{Conclusion}

The SAGE described here has lead to the identification of 66 novel genes expressed in $P$. berghei sporozoites. These novel sporozoite expressed genes, especially those expressed at high levels in salivary gland sporozoites, are likely to play a role in Plasmodium infectivity in the mammalian host.

\section{Methods \\ Mosquito Infections}

A. gambiae (Yaounde strain) and Anopheles stephensi (A. stephensi) (Sda500 strain) mosquitoes were reared at the Centre for Production and Infection of Anopheles at the Pasteur Institute under standard conditions [42]. 3-4 day old female mosquitoes were fed on anaesthetised $P$. berghei infected mice. A recombinant $P$. berghei strain expressing GFP in late midgut stages and SG of mosquitoes was used [43].

\section{Construction of SAGE libraries}

The construction of the SAGE libraries has been described elsewhere [16]. Briefly, 2 libraries were constructed from SG of infected A. gambiae mosquitoes: one 14 days (early stage of infection) and the other 18 days (stage at which sporozoites are considered to be fully infectious) after feeding on $P$. berghei infected mice. Two control libraries were made from SG of mosquitoes 14 and 15-18 days post-feeding on uninfected mice.

\section{Analysis of Tag Sequences}

The analysis of tag sequences has been described in detail in [16]. Tag sequences found only in libraries from the infected mosquitoes were considered as potential $P$. berghei sequences. BLASTN comparisons were performed against the library of $P$. berghei contigs and annotated genes obtained from the ftp site of the Sanger Institute $P$. 
berghei genome project (version 12 August 2005). Sequences of genes unambiguously identified by tags were aligned to EST_others (i. e. non-human, non-mouse EST sequences) at the National Center for Biotechnology Information via the Plasmodium genome consortium PlasmoDB.

\section{Real-time Quantitative RT-PCR}

Real time qPCR was performed on cDNA preparations using the SYBR green detection system and the ABI Prism 7900 sequence detector (Applied Biosystems) according to manufacturer's instructions. Midgut and SG sporozoites were isolated from A. gambiae mosquitoes infected with $P$. berghei at $\mathrm{d} 14$ and $\mathrm{d} 18$ after the blood meal. Under these conditions, the mean number of sporozoites isolated from midguts was $5500 \pm 200(\mathrm{~d} 14)$ and $7500 \pm$ 1700 (d18), and the mean number of sporozoites from SG was $1500 \pm 20(\mathrm{~d} 14)$ and $3900 \pm 1200(\mathrm{~d} 18)$. SG sporozoites were also isolated from A. stephensi mosquitoes infected with $P$. berghei with slightly higher mean numbers of sporozoites per gland: $3300 \pm 250$ on d14 and $17000 \pm 1800$ on d18. RNA was extracted with TriReagent, DNAse treated, and cDNAs synthesised with Superscript II reverse transcriptase (Invitrogen) using random primers. Three independent RNA preparations were made for each sample. cDNAS of $P$. berghei ookinetes and asynchronous blood stages were prepared as described in [44]. PCR conditions were 1 cycle of $50^{\circ} \mathrm{C}$ for $2 \mathrm{~min}$, followed by $95^{\circ} \mathrm{C}$ for $10 \mathrm{~min}$, then 40 cycles of $\left(95^{\circ} \mathrm{C} 15 \mathrm{sec}, 60^{\circ} \mathrm{C} 1 \mathrm{~min}\right)$. qPCR was performed in triplicate. The standard curve was analysed for all primers and gave amplification efficiencies of 90-100\%. Data was analysed with SDS 2.1 software and with geNORM Visual Basic application for Microsoft_Excel as described by Vandesompele et al. to determine the best reference gene for the qPCR [45]. This approach relies on the principle that the expression of a perfect reference gene should be identical in all samples, independent of experimental conditions or cell type. For the comparaison between midgut and salivary gland samples the Circumsporozoite gene (CS), PB001026.00.0, was determined to be the best reference gene and the expression of genes of interest were subsequently normalized to the geometric mean of this reference. The normalized gene expression was then calculated with the Q-Gene software [46]. For the qPCR analysis between different tissues the gene coding for hsp70 was found to be the best reference. The list of primers used for qPCR analysis is provided in Additional file 4.

\section{RT-PCR}

cDNA samples were prepared as for qPCR except that half of the mRNA was not treated with reverse transcriptase. PCR was performed with 1 unit of Platinum Taq polymerase, in manufacturer's buffer (InVitrogen) and $1.5 \mathrm{mM}$ $\mathrm{MgCl}_{2}$. PCR conditions were : 1 cycle at $94^{\circ} \mathrm{C}$ for $2 \mathrm{~min}$,
40 cycles of $\left(94^{\circ} \mathrm{C}\right.$ for $20 \mathrm{sec}, 55^{\circ} \mathrm{C}$ or $52^{\circ} \mathrm{C}$ for $35 \mathrm{sec}$, $68^{\circ} \mathrm{C}$ for $1 \mathrm{~min}$ ) and $1 \mathrm{cycle}$ at $68^{\circ} \mathrm{C}$ for $10 \mathrm{~min}$. Primers used for RT-PCR are shown in Additional file 4.

\section{Abbreviations}

SAGE: Serial Analysis of Gene Expression

SG: salivary glands

cDNA: complementary DNA

ESTs: expressed sequence tags

BLAST: Basic Local Alignment Search Tool

ORF: open reading frame

qPCR: quantitative polymerase chain reaction

KDa: kilodaltons

\section{Authors' contributions}

IR-C was responsible for the conception of the SAGE, performed experiments, analysed data and wrote the manuscript.

TC, BB, SP and EB performed experiments, acquired and interpreted data and provided tables, figures and revised the manuscript.

JB and PC constructed the SAGE libraries and revised the manuscript.

RM and PBrey critically revised the manuscript

PBaldacci analysed the data and wrote the paper.

All authors read and approved the final manuscript.

\section{Additional material}

\section{Additional file 1}

List and annotation of the 530 tag sequences with hits in the P. berghei genome (sheet 1). BLASTN analysis against A. gambiae genome and EST sequences of the tags found specifically in infected salivary gland libraries that did not align with $\mathrm{P}$. berghei genome (sheet 2).

Click here for file

[http://www.biomedcentral.com/content/supplementary/14712164-8-466-S1.xls] 


\section{Additional file 2 \\ Compilation of information in databases with BLASTN alignments and annotation of the $123 \mathrm{P}$. berghei genes with their putative fonction, pre- dicted molecular weight and domains, expression data and P. falciparum orthologues. \\ Click here for file \\ [http://www.biomedcentral.com/content/supplementary/1471- 2164-8-466-S2.xls] \\ Additional file 3 \\ Confirmation by RT-PCR of the expression of 66 SIS genes in salivary gland sporozoites. The SIS genes tested are indicated above the wells on cDNA samples $(+R T)$ and controls for DNA contamination (-RT). The size marker is 100 nt Smart ladder (Eurogentec). G refers to gel number as indicated in Additional file 4. \\ Click here for file \\ [http://www.biomedcentral.com/content/supplementary/1471- \\ 2164-8-466-S3.PDF] \\ Additional file 4 \\ Primers used for annotation and qPCR. Sheet1: List of primers used for annotation and results of RT-PCR analysis. Some PCR fragments have been sequenced and their sequences submitted to EMBL database (acces- sion numbers are indicated in columns $L$ and $M$ ). Column " $E$ " refers to the gel in Additional file 3. \\ Click here for file \\ [http://www.biomedcentral.com/content/supplementary/1471- 2164-8-466-S4.xls]}

\section{Acknowledgements}

We thank the CEPIA for mosquito rearing and Jean Sautereau for infections. The work was supported by grants from the Institut Pasteur (Grand Programme Horizontal Anophèle), CNRS- PAL+, Research Program on Parasitic Diseases Sanofi-Aventis/Ministry for Research, the European Commission (FP6 BioMalPar Network of Excellence) and Howard Hughes Medical Institute. T. C. and B. B. are post-doctoral fellows funded by the Research Program on Parasitic Diseases Sanofi-Aventis/Ministry for Research. E. B. is funded by the Délégation Générale à l'Armement.

\section{References}

I. Baldacci P, Menard R: The elusive malaria sporozoite in the mammalian host. Mol Microbiol 2004, 54:298-306.

2. Frevert U, Engelmann S, Zougbede S, Stange J, Ng B, Matuschewski K, Liebes L, Yee H: Intravital observation of Plasmodium berghei sporozoite infection of the liver. PLoS Biol 2005, 3:el92.

3. Amino R, Thiberge S, Martin B, Celli S, Shorte S, Frischknecht F, Menard R: Quantitative imaging of Plasmodium transmission from mosquito to mammal. Nat Med 2006, I 2:220-224.

4. Tarun AS, Baer K, Dumpit RF, Gray S, Lejarcegui N, Frevert U, Kappe $\mathrm{SH}$ : Quantitative isolation and in vivo imaging of malaria parasite liver stages. Int J Parasitol 2006.

5. Sturm A, Amino R, van de SC, Regen T, Retzlaff S, Rennenberg A, Krueger A, Pollok JM, Menard R, Heussler VT: Manipulation of host hepatocytes by the malaria parasite for delivery into liver sinusoids. Science 2006, 3 I3: I 287-1290.

6. Nussenzweig R, Vanderberg J, Most H: Protective immunity produced by the injection of $x$-irradiated sporozoites of Plasmodium berghei. IV. Dose response, specificity and humoral immunity. Mil Med 1969, I34: I I76-I I82.

7. Mueller AK, Camargo N, Kaiser K, Andorfer C, Frevert U, Matuschewski K, Kappe SH: Plasmodium liver stage developmental arrest by depletion of a protein at the parasite-host interface. Proc Natl Acad Sci U S A 2005, 1 02:3022-3027.
8. Mueller AK, Labaied M, Kappe SH, Matuschewski K: Genetically modified Plasmodium parasites as a protective experimental malaria vaccine. Nature 2005, 433: $164-167$.

9. Le Roch KG, Zhou Y, Blair PL, Grainger M, Moch JK, Haynes JD, De La Vega P, Holder AA, Batalov S, Carucci DJ, Winzeler EA: Discovery of gene function by expression profiling of the malaria parasite life cycle. Science 2003, 30 I:|503-I508.

10. Florens L, Washburn MP, Raine JD, Anthony RM, Grainger M, Haynes JD, Moch JK, Muster N, Sacci JB, Tabb DL, Witney AA, Wolters D, Wu Y, Gardner MJ, Holder AA, Sinden RE, Yates JR, Carucci DJ: A proteomic view of the Plasmodium falciparum life cycle. Nature 2002, 41 9:520-526.

II. Hall N, Karras M, Raine JD, Carlton JM, Kooij TW, Berriman M, Florens L, Janssen CS, Pain A, Christophides GK, James K, Rutherford K, Harris B, Harris D, Churcher C, Quail MA, Ormond D, Doggett J, Trueman HE, Mendoza J, Bidwell SL, Rajandream MA, Carucci DJ, Yates JR 3rd, Kafatos FC, Janse CJ, Barrell B, Turner CM, Waters AP, Sinden RE: A comprehensive survey of the Plasmodium life cycle by genomic, transcriptomic, and proteomic analyses. Science 2005, 307:82-86.

12. Carlton JM, Angiuoli SV, Suh BB, Kooij TW, Pertea M, Silva JC, Ermolaeva MD, Allen JE, Selengut JD, Koo HL, Peterson JD, Pop M, Kosack DS, Shumway MF, Bidwell SL, Shallom SJ, van Aken SE, Riedmuller SB, Feldblyum TV, Cho JK, Quackenbush J, Sedegah M, Shoaibi A, Cummings LM, Florens L, Yates JR, Raine JD, Sinden RE, Harris MA, Cunningham DA, Preiser PR, Bergman LW, Vaidya $A B$, van Lin $L H$, Janse C), Waters AP, Smith HO, White OR, Salzberg SL, Venter JC, Fraser CM, Hoffman SL, Gardner MJ, Carucci DJ: Genome sequence and comparative analysis of the model rodent malaria parasite Plasmodium yoelii yoelii. Nature 2002, 4 I 9:5 I 2-5 I 9.

13. Kappe SH, Gardner MJ, Brown SM, Ross J, Matuschewski K, Ribeiro JM, Adams JH, Quackenbush J, Cho J, Carucci DJ, Hoffman SL, Nussenzweig V: Exploring the transcriptome of the malaria sporozoite stage. Proc Natl Acad Sci U S A 2001, 98:9895-9900.

14. Matuschewski K, Ross J, Brown SM, Kaiser K, Nussenzweig V, Kappe $\mathrm{SH}$ : Infectivity-associated changes in the transcriptional repertoire of the malaria parasite sporozoite stage. J Biol Chem 2002, 277:41948-41953.

15. Kaiser K, Matuschewski K, Camargo N, Ross J, Kappe SH: Differential transcriptome profiling identifies Plasmodium genes encoding pre-erythrocytic stage-specific proteins. Mol Microbiol 2004, 5I:I22I-1232.

16. Rosinski-Chupin I, Briolay J, Brouilly P, Perrot S, Gomez SM, Chertemps T, Roth CW, Keime C, Gandrillon O, Couble P, Brey PT: SAGE analysis of mosquito salivary gland transcriptomes during Plasmodium invasion. Cell Microbiol 2007, 9:708-724.

17. Velculescu VE, Zhang L, Vogelstein B, Kinzler KW: Serial analysis of gene expression. Science 1995, 270:484-487.

18. Knox DP, Skuce PJ: SAGE and the quantitative analysis of gene expression in parasites. Trends Parasitol 2005, 2 I:322-326.

19. Velculescu VE, Vogelstein B, Kinzler KW: Analysing uncharted transcriptomes with SAGE. Trends Genet 2000, 16:423-425.

20. Pleasance ED, Marra MA, Jones SJ: Assessment of SAGE in transcript identification. Genome Res 2003, I3:1203-1215.

21. Ishino T, Chinzei Y, Yuda M: Two proteins with 6-cys motifs are required for malarial parasites to commit to infection of the hepatocyte. Mol Microbiol 2005, 58: I 264-1275.

22. Sultan AA, Thathy V, Frevert U, Robson KJ, Crisanti A, Nussenzweig $\mathrm{V}$, Nussenzweig RS, Menard R: TRAP is necessary for gliding motility and infectivity of plasmodium sporozoites. Cell 1997, 90:51 I-522.

23. Wang Q, Brown S, Roos DS, Nussenzweig V, Bhanot P: Transcriptome of axenic liver stages of Plasmodium yoelii. Mol Biochem Parasitol 2004, 137:161-168.

24. Munasinghe A, Patankar S, Cook BP, Madden SL, Martin RK, Kyle DE, Shoaibi A, Cummings LM, Wirth DF: Serial analysis of gene expression (SAGE) in Plasmodium falciparum: application of the technique to A-T rich genomes. Mol Biochem Parasitol 200I, I | 3:23-34.

25. Bhanot P, Schauer K, Coppens I, Nussenzweig V: A surface phospholipase is involved in the migration of plasmodium sporozoites through cells. J Biol Chem 2005, 280:6752-6760.

26. Ishino T, Chinzei $Y$, Yuda M: A Plasmodium sporozoite protein with a membrane attack complex domain is required for breaching the liver sinusoidal cell layer prior to hepatocyte infection. Cell Microbiol 2005, 7:199-208. 
27. Labaied M, Camargo N, Kappe SH: Depletion of the Plasmodium berghei thrombospondin-related sporozoite protein reveals a role in host cell entry by sporozoites. Mol Biochem Parasitol 2007, I 53:158-166.

28. Aly AS, Matuschewski K: A malarial cysteine protease is necessary for Plasmodium sporozoite egress from oocysts. J Exp Med 2005, 202:225-230.

29. Thompson J, Janse CJ, Waters AP: Comparative genomics in Plasmodium: a tool for the identification of genes and functional analysis. Mol Biochem Parasitol 200 I, I I 8: I47-I54.

30. van Dijk MR, Douradinha B, Franke-Fayard B, Heussler V, van Dooren MW, van Schaijk B, van Gemert G], Sauerwein RW, Mota MM, Waters AP, Janse CJ: Genetically attenuated, P36p-deficient malarial sporozoites induce protective immunity and apoptosis of infected liver cells. Proc Natl Acad Sci U S A 2005, 102:12194-12199.

31. van Dijk MR, Janse CJ, Thompson J, Waters AP, Braks JA, Dodemont HJ, Stunnenberg HG, van Gemert GJ, Sauerwein RW, Eling W: A central role for $\mathrm{P} 48 / 45$ in malaria parasite male gamete fertility. Cell 200I, 104:153-164.

32. Ishino T, Yano K, Chinzei Y, Yuda M: Cell-passage activity is required for the malarial parasite to cross the liver sinusoidal cell layer. PLoS Biol 2004, 2:

33. Kariu T, Yuda M, Yano K, Chinzei Y: MAEBL is essential for malarial sporozoite infection of the mosquito salivary gland. J Exp Med 2002, 195: I3|7-I 323.

34. Buscaglia CA, Coppens I, Hol WG, Nussenzweig V: Sites of interaction between aldolase and thrombospondin-related anonymous protein in plasmodium. Mol Biol Cell 2003, 14:4947-4957.

35. Jewett TJ, Sibley LD: Aldolase forms a bridge between cell surface adhesins and the actin cytoskeleton in apicomplexan parasites. Molecular cell 2003, I I:885-894.

36. Baker RP, Wijetilaka R, Urban S: Two Plasmodium rhomboid proteases preferentially cleave different adhesins implicated in all invasive stages of malaria. PLoS Pathog 2006, 2: el I3.

37. Cui L, Fan Q, Li J: The malaria parasite Plasmodium falciparum encodes members of the Puf RNA-binding protein family with conserved RNA binding activity. Nucleic Acids Res 2002, 30:4607-46I7.

38. Patankar S, Munasinghe A, Shoaibi A, Cummings LM, Wirth DF: Serial analysis of gene expression in Plasmodium falciparum reveals the global expression profile of erythrocytic stages and the presence of anti-sense transcripts in the malarial parasite. Mol Biol Cell 200I, I 2:3I I4-3I25.

39. Gunasekera AM, Patankar S, Schug J, Eisen G, Kissinger J, Roos D, Wirth DF: Widespread distribution of antisense transcripts in the Plasmodium falciparum genome. Mol Biochem Parasitol 2004, 136:35-42.

40. Ralph SA, Bischoff E, Mattei D, Sismeiro O, Dillies MA, Guigon G, Coppee JY, David PH, Scherf A: Transcriptome analysis of antigenic variation in Plasmodium falciparum-var silencing is not dependent on antisense RNA. Genome Biol 2005, 6:R93.

41. Vanderberg JP: Development of infectivity by the Plasmodium berghei sporozoite. J Parasitol 1975, 6I:43-50.

42. Frischknecht F, Martin B, Thiery I, Bourgouin C, Menard R: Using green fluorescent malaria parasites to screen for permissive vector mosquitoes. Malar J 2006, 5:23.

43. Natarajan R, Thathy V, Mota MM, Hafalla JC, Menard R, Vernick KD: Fluorescent Plasmodium berghei sporozoites and pre-erythrocytic stages: a new tool to study mosquito and mammalian host interactions with malaria parasites. Cell Microbiol 200I, 3:37I-379.

44. Raibaud A, Brahimi K, Roth CW, Brey PT, Faust DM: Differential gene expression in the ookinete stage of the malaria parasite Plasmodium berghei. Mol Biochem Parasitol 2006, I 50: I07-I I3.

45. Vandesompele J, De Preter K, Pattyn F, Poppe B, Van Roy N, De Paepe A, Speleman F: Accurate normalization of real-time quantitative RT-PCR data by geometric averaging of multiple internal control genes. Genome Biol 2002, 3:RESEARCH0034.

46. Muller PY, Janovjak H, Miserez AR, Dobbie Z: Processing of gene expression data generated by quantitative real-time RTPCR. BioTechniques 2002, 32:1372-1374. 1376, |378-1379
Publish with Biomed Central and every scientist can read your work free of charge

"BioMed Central will be the most significant development for disseminating the results of biomedical research in our lifetime. "

Sir Paul Nurse, Cancer Research UK

Your research papers will be:

- available free of charge to the entire biomedical community

- peer reviewed and published immediately upon acceptance

- cited in PubMed and archived on PubMed Central

- yours - you keep the copyright

Submit your manuscript here:

http://www.biomedcentral.com/info/publishing_adv.asp
BiolMedcentral 